\title{
An analysis of monetary voluntary contributions for cultural resources: the case of the British Museum
}

\author{
Alexandros ApOstolakis AND SHABBAR JAFFry \\ Department of Economics, Portsmouth Business School, University of Portsmouth, \\ Richmond Building, Portland Street, Portsmouth P01 3DE, UK. \\ E-mail: alex.apostolakis@port.ac.uk; shabbar.jaffry@port.ac.uk. \\ (Corresponding author: Alexandros Apostolakis.)
}

\begin{abstract}
The study considers the factors affecting the levels of individual voluntary contributions for cultural tourist not-for-profit resources. The paper takes the British Museum (BM), London, as an example. The $\mathrm{BM}$ is the leading free-entry cultural tourist attraction in London. However, funding for the BM has decreased by over $30 \%$ in the past 10 years. The results illustrate the effect of formal and informal 'communities of participation' that generate obligations for voluntary contributions towards arts and cultural resources. The BM, the authors argue, should try to invest in cultural network enhancing infrastructure that could potentially encourage visitors to contribute voluntarily. It should also influence trust levels among potential donors by becoming more accountable. The authors argue that these policy initiatives could lower the transaction costs of pro-social behaviour.
\end{abstract}

Keywords: voluntary contributions; willingness to contribute; ordered probit; cultural resources; British Museum

As a result of recent worldwide pressures on government funding (Anderson, 1998; Bailey and Falconer, 1998; Trupiano, 2005), coupled with calls for a greater degree of accountability and justification of public expenditure, cultural attractions have to generate income through their own activities to sustain their operations at current levels (Jaffry and Apostolakis, 2011). Illustrative perhaps of the above policy predicaments, governments are actively encouraging cultural resource managers and policymakers to find ways to raise much needed capital to fund their activities (UK Department for Media, Culture and Sport, 2000, 2002, 2005). Practically, this means attracting more private sponsorships, 
raising funds from better exploitation of own resources and, most importantly, generating more income through individual voluntary contributions.

This call to cultural heritage resources to maximize revenue raised through own activities has focused mainly on individual voluntary contributions (for example, voluntary contributions through the entry gates) and greater targeting of individual donors (Department for Media, Culture and Sport, 2005; Gurian, 2005; Steele, 2010). Indicative of the significance of voluntary contributions on levels of self-generated income, Heilbrun and Gray (2001) reported that individual voluntary contributions account for about one-third of arts and cultural organizations' total earned income. As a result, they now represent an important part of their income generating resources (Tepper, 2005).

However, the problem cultural tourist not-for-profit organizations face is that the money currently raised through individual voluntary contributions is not enough to cover the reduction in government funding. According to the literature (De Kremer, 2003), the problem arises because individual visitors do not have an incentive to contribute voluntarily during their visit. Hence, cultural establishments are faced with a social dilemma in the sense that individual visitors are better off consuming the cultural services, without making any contribution towards costs. In this respect, the social response towards voluntary giving for arts and culture has been caught in a trap by a society that has learned to interact on the basis of its purchasing power (Fenton et al, 1999).

The objective of this paper is to provide evidence-based insights for policymakers and managers regarding a more effective targeting of those individuals most likely to contribute voluntarily towards not-for-profit cultural resources. This empirical study could allow managers and policymakers to analyse whether visitors are likely to contribute voluntarily to cultural resources and by how much. Following Webb et al (2000) and Jaffry and Apostolakis (2011), the recent popularity of this issue in the literature illustrates its significance and timeliness for cultural heritage organizations. This paper will identify who is more likely to contribute voluntarily to not-for-profit cultural organizations and by how much. It will do so by evaluating the importance of a number of different variables on visitors' decisions to contribute voluntarily to cultural heritage resources. In other words, the focus of the paper is on the effective targeting of individuals who are more likely to donate to cultural organizations.

In particular, the objective of this empirical research is to identify the determinants of trust for pro-social behaviour. The thesis of the paper maintains that the factors that affect trust also determine pro-social behaviour in the form of voluntary contributions for arts and cultural resources. Indeed, trust is a recurrent issue in the area (Webb et al, 2000).

Measuring the additional contribution that each group of visitors would be willing to make could provide interesting insights to managers of cultural attractions, such as the British Museum (BM) (Jaffry and Apostolakis, 2011). The $\mathrm{BM}$ in London is the most significant cultural heritage attraction in the UK. Although there are other equally significant cultural resources in London, the current endeavour translates individual preferences into monetary estimates. As a result, we have avoided making any value judgments regarding the cultural value of the resource. Given its status as a 'must-see attraction' the BM 
contributes to the competitiveness of London and the UK as a tourist destination. In fact, when comparing the various cultural tourist resources, the $\mathrm{BM}$ is the leading free-entry cultural attraction in the UK, with almost 6 million visitors passing through its gates every year. The question then is, how does the $\mathrm{BM}$ manage to capitalize its popularity in terms of generating revenue through individual voluntary contributions at the gates?

The rest of the paper is structured as follows. The next section summarizes the literature on charitable/voluntary giving and orients the current study within the literature. The subsequent section describes the empirical data on which the analysis is based and outlines the empirical method (ordered probit model) used for the data analysis. In the fourth section, we present the empirical results. We then, in the fifth section, propose policy implications based on our evaluation of the empirical results. In the final section, we offer our conclusions.

\section{Literature review}

The paper maintains that voluntary giving (willingness to contribute voluntarily) is the result of a feeling of trust towards cultural organizations. Johnson and Garbarino (1999) point out that frequent subscribers assign substantially higher levels of trust to repertory theatres in the USA, as compared to non-subscribers. More recently, Bertacchini et al (2010) concluded that the recipient organization's fiscal accountability had a positive effect on donors' behaviour patterns.

A number of papers based on case studies material have also appeared recently to shed light in voluntary giving activity. In particular, Webb et al (2000) reported that trust in the organization had a major effect on donation behaviour and intensity. On this basis, it is not surprising that Hoge and Yang (1994), Schervish and Havens (1997), as well as Bekkers (2006) and Ranganathan and Henley (2008), reported that religious organizations in the UK were deemed among the most trustworthy (and correspondingly, those most likely to receive higher levels of voluntary giving). According to Apinunmahakul and Devlin (2008), Wilson (2000) and Schervish and Havens (1998), the decision to contribute voluntarily is a function of one's familiarity with a community, or network of individuals, rather than the availability and quality of the service per se. In short, the authors provide evidence towards a positive relationship between trust towards others (in the form of formal and/or informal relationships) and the intention to engage in pro-social behaviour. This relationship has also been supported by Putnam (2000) and Brooks (2005) in their respective studies.

An examination of the relevant literature identifies a number of 'solutions' to the voluntary contributions problem. On the one hand, some research focuses on the donor's relationship or links, either formal or informal, with the notfor-profit organization (Schervish and Havens, 1998; Atkinson, 2009; Krishnamurthy and Tripathi, 2009). These papers argue that individuals donate to not-for-profit organizations providing they have strong links with that organization. These studies strive to explain the act of charitable giving through the donor's close involvement and identification with the needs and aspirations of the organization (Schervish and Havens, 1998). 
On the other hand, Apinunmahakul and Devlin (2008), Wilson and Pimm (1996), and, to a certain extent, Schervish and Havens (1998), all support the argument that formal or informal communities of participation (or social networks, according to Apinunmahakul and Devlin, 2008) create trustworthy relationships either within the confines of a particular organization (such as the 'Friends of the BM'), or in a more loosely defined context (a network of museum-goers).

These networks of formal and informal participation groups would enhance awareness of needs and the likelihood of giving. Webb et al (2000) have emphasized the importance of awareness of need, arguing that "the awareness variables are most suitable to distinguish between donors and non-donors' (Schlegelmilch, 1998: 35). At the same time, the role of trust and confidence is fundamental in every economic transaction as a potential transaction cost disturbance. One could assume that the existence of these formal and informal communities of participation would lead to a reduction in transaction costs associated with the community and the organization (Labonne and Chase, 2010). In this way, lower transaction costs would bear a positive effect on voluntary contributions.

The examination of the relevant literature will also reveal one additional source of explanation for acts of voluntary giving for arts and culture resources. Proponents of this approach (Putnam, 2000; Wilson, 2000; Brooks, 2005; Bertacchini et al, 2010) argue that voluntary giving is the result of the individual's upbringing, social trust, and political and ideological engagements. Education is thus a very good determinant of voluntary giving behaviour (Reed and Selbee, 2000; Holmes, 2009). The social/cultural capital argument incorporates an individual perspective (individual characteristics) and a community perspective (community relationships). According to Putnam (2000), the existence of social and cultural capital increases the likelihood of voluntary donations and charity in general. The central argument in this approach focuses upon the direct involvement in the activities of the respective not-for-profit organization.

\section{Methodology}

Data for the empirical investigation were collected through the implementation of a stated preference discrete choice modelling survey questionnaire supported financially by the British Academy. The purpose of the questionnaire was to examine respondents' willingness to contribute voluntarily to the $\mathrm{BM}$ as a result of a number of hypothetical policy initiatives. In total, 500 questionnaires were distributed. A team of researchers was assigned to approach potential respondents, at random, prior to their entry into the $\mathrm{BM}$. The questionnaire also collected information on respondents' socio-demographic profiles as well as visitation-specific information.

Existing studies examining voluntary contributions in a cultural heritage tourist setting have focused on whether or not individuals (visitors and/or tourists) donate to cultural resources (Bille Hansen, 1997; Steiner, 1997; Tohmo, 2004; Lampi and Orth, 2009). The phenomenon they were examining was either bivariate, or multivariate. Thus, the majority of studies in the area have 
used multiple regression, probit or logit models (Yang and Raehsler, 2005). The current study differentiates itself from the studies above in the sense that the observation of interest is of an ordinal nature.

As far as this empirical exercise is concerned, the dependent variable used required respondents to select from a range of values, the amount of money they were more likely to contribute voluntarily to the BM. In this empirical application, the dependent variable takes four values (0 to 3). Given that the dependent variable is discrete, multiple and ranked in nature, the analysis has opted for the use of ordered probit models (Yang and Raehsler, 2005; Oliveira and Pereira, 2008). Thus, the empirical analysis uses an extension of the binary probit model for the analysis of individuals' willingness to contribute voluntarily to the $\mathrm{BM}$, based on the fact that the dependent variable is ordinal in nature (in the sense that response category $0<$ response category $1<$ response category $2<$ response category 3).

Ordered-response models of individual choice take into consideration the indexed nature of the dependent variable; in this context, the value of individual voluntary contributions measured in pounds sterling. This factor represents a considerable improvement over multinomial logit and probit models since ordered probit models require estimation of fewer parameters (thus increasing the degrees of freedom available for estimation) and do not exhibit the undesirable property of independence of irrelevant alternatives (IIA) (Greene, 2000). The empirical model specification used is as follows:

$$
Y_{n}^{*}=X_{n} \beta+\varepsilon_{n}
$$

where $Y_{n}^{*}=$ the latent and continuous (ordinal) measure of intention to voluntarily contribute to the BM (measured in pounds sterling) by the $n$th visitor, $\boldsymbol{X}_{n}=$ the standard vector of explanatory variables specific for the $n$th individual (comprised of a number of socio-demographic, and visitor specific attributes), $\beta=$ a vector of parameters to be estimated and $\varepsilon_{n}=$ a random error term (assumed to follow a standard normal distribution).

Further, given the ordinal nature of the dependent variable, the observed and coded discrete intention to voluntary contribute variable, $Y_{n}$, is determined from the model as follows:

$$
Y n= \begin{cases}0 & \text { if }-\infty \leq Y n \leq \mu 1 \text { (no intention to voluntary contribute) } \\ 1 & \text { if } \mu 1 \leq Y n \leq \mu 2 \text { (intention to contribute up to £1.99) } \\ 2 & \text { if } \mu 2 \leq Y n \leq \mu 3 \text { (intention to contribute up to £3.99) } \\ 3 & \text { if } \mu 3 \leq Y n \leq \mu 4 \text { (intention to contribute more than £4.00) }\end{cases}
$$

where $\mu 1, \mu 2, \mu 3$ and $\mu 4$ are threshold variables in the probit model to be estimated. Given the nature of the ordered classes, the interpretation of the beta parameters $(\beta \mathrm{s})$ in the model is as follows: positive signs indicate higher individual willingness to voluntarily contribute, while a negative sign suggests the opposite (Kockelman and Kweon, 2002). 


\section{Results}

Table 1 presents the definitions and descriptive statistics of the variables used in the analysis. It appears that more than one-quarter of respondents had visited the BM as part of a tourist visit (around $27.5 \%$ of visitors), whereas the majority of respondents argued that the primary reason for visiting London was the BM itself (around $45 \%$ of the sample). This confirms the point regarding the status of the $\mathrm{BM}$ as the most significant cultural tourist attraction in London. Leisure visitors (those visiting the BM as part of a day out) represented about $18 \%$ of the sample. As far as the other variables are concerned, the results from Table 1 suggest that the majority of visitors to the BM are first-time visitors (more than half of respondents), whereas the majority of repeat visitors have visited the BM once or twice in the past 5 years (29\%). This may be another indication that the $\mathrm{BM}$ enhances the tourism product of the capital with its 'must-see' status. Finally, the majority of visitors (54.6\% of respondents) reported a high level of disposable income (more than $£ 25,000$ ), while $37.5 \%$ reported a middle of the range income and about $7 \%$ reported an income below $£ 12,500$.

Unfortunately, the literature does not provide much information regarding visitors' profiles to the BM. The most recent independent survey conducted at the BM (Maddison and Foster, 2003) reports some information regarding the sample of visitors, whereas the information from the BM's website is in very short supply. For that reason we revert to Caygill and Leese (1993) for comparative data on visitors' socio-demographic profiles.

Table 2 reveals that there is an almost equal split as far as previous visitation and gender variables are concerned. In both of these cases, the survey results are directly comparable to those reported by Caygill and Leese (1993). Breaking up the previous visitation phenomenon furthermore, the report indicates that most of the repeat visitors have visited once or twice in the past (almost 30\%), or up to four times before (14\%). Visitors to the BM tend to be relatively young (27\% of those in the $21-30$ age category, and $35 \%$ in the $31-40$ age category). This finding is also in broad accordance to what was reported by Caygill and Leese (1993). The percentage of visitors coming from London (almost 52\%) appears to be rather high, whereas the percentage of overseas visitors is lower than anticipated (23\%). However, both Maddison and Foster (2003) and the information from the BM's website seem to report almost identical information. Although the survey seems to be over-representative of high income respondents, these results are in broad agreement to the findings reported by Maddison and Foster (2003).

The analysis considers next the econometric analysis and the effect of a number of factors, on voluntary contribution levels at the BM. The results from the ordered probit model specification are analysed with reference to (base level attributes) a female visitor, living in the UK (outside London), under 20 years of age, with high income levels, having visited the $\mathrm{BM}$ more than six times in the last 5 years, not a member of other museums or cultural organizations, whose normal occupation is not connected to cultural resources or museums, whose purpose in visiting London was a generic one, and whose educational qualifications were not stated in the survey questionnaire. Table 3 summarizes the estimation results from the ordered probit regression. 
Table 1. Definitions of variables and descriptive statistics.

Variable

For holidays

For business

For the BM

specifically

For a day out

First-time visitor

Visited 1-2 times before

Visited 3-4 times before

Friend of the BM

Member of cultural organization

Live in Central

London

\section{Explanation}

Mean

SD

$0.274 \quad 0.446$

as part of a tourist visit, and 0 if otherwise

Dummy variable, 1 if the respondent has visited London as part of a business trip, and 0 if otherwise

Dummy variable, 1 if the respondent has visited London in order to visit the British Museum, and 0 if otherwise

Dummy variable, 1 if the respondent has visited London as part of a leisure day out, and 0 if otherwise

$0.176 \quad 0.566$

1.3681 .494

$0.704 \quad 1.523$

$0.488 \quad 0.499$

British Museum for the first time, 0 if otherwise

Dummy variable, 1 if the respondent has visited the British Museum once or twice in the past, 0 if otherwise

Dummy variable, 1 if the respondent has visited the British Museum 3 or 4 times in the past, 0 if otherwise

Dummy variable, 1 if the respondent is part of the

'Friends of the BM' network, 0 if otherwise

0.2920 .454

$0.138 \quad 0.344$

$0.590 \quad 0.491$

$0.607 \quad 0.488$

cultural organization, 0 if otherwise

Dummy variable, 1 if the respondent lives in Central

London, 0 if otherwise

$0.104 \quad 0.305$

$0.078 \quad 0.268$

$0.078 \quad 0.269$

$0.128 \quad 0.334$

0.1320 .338

$0.230 \quad 0.420$

$\begin{array}{ll}0.497 & 0.500\end{array}$

$0.060 \quad 0.237$

0.0720 .258

$0.066 \quad 0.248$

$0.102 \quad 0.302$

$0.258 \quad 0.437$

$0.021 \quad 0.140$

$0.270 \quad 0.445$

$0.348 \quad 0.476$

$0.192 \quad 0.393$ 0 if not

Dummy variable, 1 if respondent is $21-30$ years old,

0 if not

Dummy variable, 1 if respondent is $31-40$ years old, 0 if not

$41-50$ years of age Dummy variable, 1 if respondent is $41-50$ years old , 
Table 1 continued.

Variable

51-64 years of age

$65+$ years of age

Compulsory

education

Vocational education

Degree-level

education

Postgraduate

education

Income - low

Income - medium
Explanation

Mean

SD

Dummy variable, 1 if respondent is $51-64$ year old, 0 if not

Dummy variable, 1 if respondent 65 years old or older, 0 if not

Dummy variable, 1 if respondent is educated up to compulsory level, 0 if not

Dummy variable, 1 if respondent has a degree, 0 if not

$0.116 \quad 0.320$

degree, 0 if not

$0.069 \quad 0.251$

0 if not

$0.374 \quad 0.484$

Since the dependent variable increases with higher voluntary contribution categories, all coefficients with a positive sign would suggest a likelihood of higher individual voluntary contributions. The opposite would apply for all coefficients with a negative sign. Table 3 indicates that the following are associated with a higher likelihood of contributing voluntarily to the BM: those visitors travelling to London for business purposes, members of the 'Friends of the British Museum' organization, and members in other museum or cultural organizations, male visitors, visitors who are either separated or remarried, all visitors except those falling within the 21-30 age range, exhibit a positive willingness to contribute voluntarily. Conversely, those visiting the BM for the first time, repeat visitors who have been to the BM once or twice in the past, visitors who reside in Central and East London, and those belonging to the low and medium income categories exhibit statistically significant and negative willingness to contribute voluntarily.

More particularly, the results indicate that those visitors combining their visit to the $\mathrm{BM}$ with business activities are more likely to contribute voluntarily to the $\mathrm{BM}$ than visitors with a generic purpose of visit. This piece of evidence points to the fact that business tourists usually have greater flexibility in terms of their budget than other types of visitor. Thus, individuals who have combined business with a visit to the BM are more likely to reciprocate towards the BM.

The results from Table 3 also reveal a strong link between communities of participation among respondents and voluntary contribution levels towards the BM. More particularly, those respondents who were active members in either the 'Friends of the British Museum' or any other museum or cultural organization, were more likely to donate money as compared to visitors who had no association with other cultural organizations. In addition, those actively associated with other cultural organizations (being members or 'friends' in other cultural institutions) also had a positive inclination towards financially 
Table 2. Socio-demographic information from the sample and comparison with past surveys.

\section{Current Survey (2008) Caygill and Leese (1993)}

Previous visit to the $B M$

No (first time)

Repeat

Number of previous visits to the BM

1-2 times

3-4 times

5-6 times

More than 6 times

Gender

Male

Overseas

Age band

Below 20

21-30

31-40

41-50

51-64

$65+$

Educational qualification

Compulsory

Vocational

Degree level

Postgraduate
$49 \%$

$51 \%$

$14 \%$

$3 \%$

$1.5 \%$

$50 \%$

$50 \%$

$10.5 \%$

$7.8 \%$

$7.8 \%$

$13 \%$

$13 \%$

$24.5 \%$

$24 \%$

$49 \%$

$51 \%$

1 time: $12 \%$

2-3 times: $29 \%$

4-5 times: $11 \%$

6-10 times: $9 \%$

More than 10 times: 39\%

$51 \%$

$49 \%$

Inner London: 13\%

Outer London: 2\%

South East Britain: 10\%

Southwest Britain: 1\%

West and East Midlands: 3\%

North and North West: $3 \%$

Overseas: 66\%

$8 \%$

$24 \%$

$19 \%$

$17 \%$

$27 \%$

$4 \%$

$12 \%$

$28.5 \%$

$47.5 \%$

$12 \%$
$7 \%$

$53 \%$

(Another $11 \%$ reported some 'professional' qualification, while there were strong segments 'still in education (20\%), or not reporting any educational background' (9\%))

\section{Income group}

$£ 0-£ 6,500$

$£ 6,501-£ 12,500$ 
Table 3. Ordered probit model: voluntary contributions.

Attribute

Constant

For holidays

For business

For the BM specifically

For a day out

First-time Visitor

Visited 1-2 times before

Visited 3-4 times before

Friend of the BM

Member in cultural organization

Live in Central London

Live in East London

Live in South London

Live in West London

Live in North London

International visitor

Gender: male

Divorced

Widowed

Separated

Co-habiting

Married

Re-married

21-30 years of age

$31-40$ years of age

41-50 years of age

$51-64$ years of age

$65+$ years of age

Compulsory education

Vocational education

Degree-level education

Postgraduate education

Income - low

Income - medium

Threshold parameters

M (1)

M (2)

M (3)

Observations

\section{Coefficient ( $\beta$ )}

$$
\begin{gathered}
0.549(0.081)^{* * * *} \\
0.292(0.262) \\
0.260(0.052)^{* * *} \\
0.017(0.841) \\
0.009(0.881) \\
-0.787(0.000)^{*} \\
-0.453(0.000)^{*} \\
0.056(0.573) \\
0.718(0.000)^{*} \\
0.832(0.000)^{*} \\
-0.267(0.000)^{*} \\
-0.327(0.000)^{*} \\
0.098(0.257) \\
-0.066(0.363) \\
-0.023(0.754) \\
0.058(0.397) \\
0.069(0.097)^{* * *} \\
0.062(0.516) \\
-0.126(0.200) \\
0.270(0.004)^{* *} \\
0.251(0.000)^{*} \\
-0.034(0.561) \\
0.730(0.000)^{*} \\
-0.041(0.628) \\
0.154(0.080)^{* * *} \\
0.276(0.004)^{* *} \\
0.907(0.000)^{*} \\
0.673(0.002)^{* *} \\
-0.375(0.234) \\
-0.035(0.909) \\
0.213(0.491) \\
-0.098(0.754) \\
-0.193(0.043)^{* *} \\
-0.095(0.078)^{* * *} \\
\end{gathered}
$$

$0.746(0.000)^{*}$

$1.566(0.000)^{*}$

$0.649(0.001)^{*}$

3,000

Note: Standard errors are in parentheses. ${ }^{*},{ }^{* *},{ }^{* * *}$ significant at $1 \%, 5 \%$ and $10 \%$ level of significance, respectively.

supporting the BM, compared to those visitors who were not actively associated with cultural resources. Following von Neumann and Morgenstern (1944), individuals' social relations (formal or informal) embed a disposition to trust and pro-social behaviour. Visitors who were actively supporting culture and the arts were more likely to reciprocate financially towards the BM. Overall, the results from this relationship tend to confirm Schervish and Haven's (1997) 
hypothesis regarding the existence of formal and informal 'communities or groups of participation' that generate obligations for voluntary contributions towards the arts and culture (Okunade et al, 1994; Hoge, 1995; Iannacone, 1998; Heilburn and Gray, 2001; Brown and Ferris, 2002; Dokko, 2008).

Currently, there is a strong debate taking place regarding the effect of the gender variable on charitable donations (Schervish et al, 2002; Piper and Schnepf, 2007). Generally speaking, the literature tends to suggest that women are more likely to reciprocate for sociological and psychological reasons (Mesch et al, 2002). Interestingly, in the current setting, men were more likely to make voluntary contributions when visiting the BM than female visitors. Although the results in the literature are, so far, ambiguous (Frey and Meier, 2004), the results from this empirical investigation tend to suggest that males are the fairer sex.

As far as the age variable is concerned, the results show that middle-aged respondents (31-50 years of age) were more likely to contribute voluntarily than younger respondents. For the mature/senior segment (above the age of 51) the results confirm a priori expectations. Senior or mature respondents are more likely to donate to the $\mathrm{BM}$ ceteris paribus than young respondents (Andreoni, 2001; Auten and Joulfaian, 1996; Hoge and Yang, 1994). The disproportionate interest of the senior segment of the population in arts and culture is logically translated into a higher propensity to financially support the BM. The fact that mature visitors enjoy higher income and wealth levels, as well as the availability of more free time also contributes to this higher likelihood to donate. To this end, the apparent 'greying' of the population worldwide could be a positive factor for the BM.

With regard to frequency of visitation, the literature provides strong evidence to link frequency of use to increasing levels of financial support for cultural tourist not-for-profit organizations (Hoge and Yang, 1994; Webb et al, 2000; Conlin et al, 2003; Smith and McSweeney, 2007; Ranganathan and Henley, 2008). The empirical findings indicate that those visiting the BM for the first time and those who have visited the BM once or twice in the past five years are less likely to contribute voluntarily during their current visit. First-time and accidental visitors are not yet familiar with the BM and its problems; thus, they are more hesitant to help out. This is not the case for more frequent users of the attraction. In this respect, the current empirical results align more closely with those of Lampi and Orth (2009).

Thus, one could interpret and justify the above finding along the lines of the respondent's familiarity levels with the BM (Hoge and Yang, 1994; Putnam, 2000; Webb et al, 2000; Smith and McSweeney, 2007; Apinunmahakul and Devlin, 2008; Ranganathan and Henley, 2008). The point is that the more familiar an individual is with the organization, and the more aware of the organization's needs and requirements, the more likely he or she will be to donate money. The finding that adjunct visitors are less likely to reciprocate than core cultural visitors (frequent visitors attending the BM more than five times over the past 5 years) could be due to the fact that first-time and adjunct visitors are not familiar with the BM not-for-profit status and its collections or with the cultural context in general. Ranganathan and Henley (2008) and Smith and McSweeney (2007) maintain that familiarity with an organization can be developed through frequency of participation and past consumption. 
Hence, past consumption trend (for example, a long history of association with an organization) is a good predictor of pro-social behaviour (Conner et al, 2002). Thus, one obvious strategy for the Trustees of the BM would be to improve the visibility of the $\mathrm{BM}$ to the latent and adjunct segments of demand.

The empirical results also reveal that respondents from Central and East London are less likely to voluntarily contribute towards the BM than respondents from any other part of the UK. We hypothesize that this may be because these parts of London attract the less affluent parts of the capital's population. Based on the theory of neutralization (Hibbert, 2005), less affluent individuals try to eliminate the responsibility of caring for the BM through denial of responsibility. This issue of denial of responsibility and neutralization is particularly useful in trying to maintain confidence in one's own conviction, rather than making a moral stand in favour of the organization or cause.

Finally, the results from the impact of the income variable on the likelihood to donate to the BM follows initial expectations in that individuals on low and middle-range incomes are less likely to voluntarily contribute towards the BM. Those on a low income would be unable or unwilling to contribute voluntarily to the BM, unlike those visitors with high income levels. Less well-off individuals seem to deny responsibility to help towards the financial support of the BM by arguing that it is the government's responsibility, or that of people with more money to spare. This empirical result provides support for the government's policy objective of free entry for cultural heritage attractions on the basis of 'democratizing' culture and expanding participation in society.

\section{Marginal effects}

The empirical evidence presented above illustrates the effect of a number of explanatory variables on the likelihood of a visitor voluntarily contributing an amount to the BM. It does not say anything about specific voluntary contribution levels. This kind of information would be valuable for managers and policymakers interested in maximizing self-generated income for cultural heritage attractions. Table 4 presents the marginal effects for a number of different voluntary contribution levels at the BM. For the sake of clarity, we compute marginal effects as the percentage change in the probability of being in a particular category (that is, falling into a specific voluntary contribution level) as a result of a unitary change in the explanatory variables. In Table 4, the second column refers to visitors' willingness to voluntary contribute nothing (£0) towards the BM, whereas columns 3 to 5 refer to increasing levels of voluntary contributions to the BM.

As far as the impact of the generic motivation is concerned, the results indicate that tourists would be $9.7 \%$ more likely to donate something to the $\mathrm{BM}$ than respondents visiting London for any other general reason. Equally, they would be around $1.5 \%$ less likely to donate anything up to $£ 1.99$ than respondents with other generic reasons for visiting London. Whereas the results in Table 3 suggest that business visitors have a higher likelihood of donating to the $\mathrm{BM}$ cause, the results in Table 4 provide interesting information about the intensity of pro-social behaviour. To that extent, business travellers would be $9 \%$ and $1 \%$ less likely to voluntary contribute $£ 0$ and any amount up to $£ 1.99$, respectively, to the $\mathrm{BM}$ as compared to other types of visitors. 
Table 4. Marginal voluntary willingness to pay estimates (£).

$\mathrm{VWTP}=£ 0$

VWTP up to

$£ 1.99$
VWTP up to

$£ 3.99$

\section{Constant}

For holidays

For business

For the BM specifically

For a day out

First-time visitor

Visited 1-2 times before

Visited 3-4 times before

Friend of the BM

Member of cultural

organization

Live in Central London

Live in East London

Live in South London

Live in West London

Live in North London

International visitor

Gender: male

Divorced

Widowed

Separated

Co-habiting

Married

Re-married

21-30 years of age

$31-40$ years of age

41-50 years of age

51-64 years of age

$65+$ years of age

Compulsory education

Vocational education

Degree-level education

Postgraduate education

Income - low

Income - medium
0.000 (Fixed)

$-0.097(0.000)^{*}$

$-0.090(0.052)^{* * * *}$

$-0.006(0.841)$

$-0.003(0.881)$

$0.270(0.000)^{*}$

$0.164(0.000)^{*}$

$-0.019(0.015)^{* *}$

$-0.203(0.000)^{*}$

$-0.223(0.000)^{*}$

$0.097(0.000)^{*}$

$0.120(0.000)^{*}$

$-0.033(0.000)^{*}$

$0.023(0.002)^{* *}$

$0.008(0.284)$

$-0.020(0.012)^{* *}$

$-0.024(0.003)^{\text {*** }}$

$-0.021(0.008)^{* *}$

$0.045(0.000)^{*}$

$-0.087(0.000)^{*}$

$-0.082(0.000)^{*}$

$0.012(0.098)^{* * * *}$

$-0.197(0.000)^{*}$

$0.014(0.055)^{* * * *}$

$-0.052(0.000)^{*}$

$-0.091(0.000)^{*}$

$-0.239(0.000)^{*}$

$-0.186(0.000)^{*}$

$0.138(0.000)^{*}$

$0.012(0.100)^{* * * *}$

$-0.074(0.000)^{*}$

$0.034(0.000)^{*}$

$0.051(0.000)^{*}$

$0.029(0.000)^{*}$

$\begin{array}{ccc}0.000(\text { Fixed }) & 0.000(\text { Fixed }) & 0.000 \text { (Fixed) } \\ -0.016(0.000)^{*} & 0.042(0.737) & 0.072(0.149) \\ -0.010(0.062)^{* * *} & 0.041(0.220) & 0.060(0.398) \\ -0.001(0.841) & 0.002(0.821) & 0.004(0.855) \\ -0.005(0.881) & 0.001(0.870) & 0.002(0.889) \\ 0.028(0.000)^{*} & -0.117(0.322) & -0.181(0.346) \\ 0.006(0.017)^{* *} & -0.075(0.019)^{* *} & -0.096(0.499) \\ -0.002(0.007)^{* *} & 0.008(0.902) & 0.013(0.866) \\ -0.076(0.000)^{*} & 0.064(0.038)^{* *} & 0.215(0.000)^{*}\end{array}$

$-0.096(0.000)^{*} \quad 0.060(0.006)^{* *}$

$0.258(0.000)^{*}$

$0.003(0.076)^{* * *}-0.045(0.000)^{*}$

$0.001(0.599) \quad-0.056(0.000)^{*}$

$-0.005(0.000)^{*} \quad 0.014(0.860)$

$0.002(0.039)^{* *}-0.010(0.832)$

$0.009(0.355) \quad-0.003(0.950)$

$-0.002(0.003)^{* *} \quad 0.009(0.917)$

$-0.002(0.000)^{* *}$

$0.012(0.892)$

$-0.030(0.001)^{*}$

$0.009(0.901)$

$0.004(0.008)^{* *}$

$-0.020(0.594)$

$-0.019(0.000)^{*} \quad 0.036(0.757)$

$-0.016(0.000)^{*}$

$0.035(0.762)$

$0.001(0.199)$

$-0.005(0.924)$

$-0.084(0.000)^{*}$

$0.056(0.766)$

$0.001(0.135)$

$-0.006(0.906)$

$0.023(0.809)$

$0.032(0.748)$

$-0.017(0.000)^{*}$

$-0.106(0.000)^{*}$

$-0.076(0.000)^{*}$

$0.061(0.075)^{* * *}$

$0.056(0.056)^{* * *}$

$0.007(0.739)$

$-0.065(0.000)^{*}$

$-0.005(0.921)$

$0.033(0.767)$

$-0.090(0.000)^{*}$

$-0.010(0.717)$

$0.003(0.018)^{* * *}$

$\begin{array}{ll}0.034(0.008)^{* *} & -0.023(0.504) \\ 0.023(0.010)^{* *} & -0.013(0.765)\end{array}$

$-0.055(0.629)$

$-0.065(0.583)$

$0.023(0.751)$

$-0.015(0.871)$

$-0.005(0.951)$

$0.013(0.861)$

$0.016(0.832)$

$0.014(0.851)$

$-0.027(0.779)$

$0.070(0.225)$

$0.064(0.274)$

-0.007 (0.929)

$0.226(0.000)^{*}$

$-0.009(0.916)$

$0.036(0.577)$

$0.069(0.197)$

$0.284(0.000)^{*}$

$0.206(0.000)^{*}$

$-0.074(0.552)$

-0.008 (0.927)

$0.049(0.372)$

$-0.021(0.819)$

$-0.031(0.756)$

$-0.019(0.839)$

Notes: Standard errors are in parentheses. ${ }^{*},{ }^{* *},{ }^{* * *}$ Significant at $1 \%, 5 \%$ and $10 \%$ level of significance, respectively.

The results concerning frequency of visitation to the $\mathrm{BM}$ are also quite revealing. Visitors with limited exposure to and familiarity (and thus limited awareness) with the BM and its collections (first time and adjunct visitors) are more likely to donate nothing than the very frequent or core cultural visitors. This piece of evidence confirms earlier findings and empirical analysis in the literature. In particular, first-time and adjunct respondents (1-2 visits) are 27\% and $16.5 \%$ more likely to donate nothing during their visit than very frequent visitors. At the same time, adjunct visitors are $7.5 \%$ less likely to donate 
anything up to $£ 3.99$ to the BM than core cultural visitors. All this evidence suggests that individuals with no or very limited physical exposure to the BM are less likely to support it financially. Interestingly, this piece of evidence seems to concur with what is reported in the literature regarding the awareness of a particular issue and levels of voluntary contributions at museums (Lampi and Orth, 2009). Hence, those with higher levels of familiarity and awareness for cultural tourist organizations are also more likely to trust that the organization will make good use of this money, and are therefore more likely to donate.

This conveys a clear message to BM managers and policymakers that they will have to communicate much more strongly the contribution the $\mathrm{BM}$ is making to society, and to introduce initiatives and strategies aiming for a better positioning of the BM brand within the cultural tourism area. In this way, BM managers and cultural policymakers could achieve a twofold objective. On the one hand, they could improve the brand name of the museum. This is important because many individuals do not take rational decisions when it comes to voluntary donations, but instead rely on the organization's exposure and recognition (Supphellen and Nelson 2001). On the other hand, policymakers could raise public awareness of the funding problems facing the BM.

Relevant research in the area has found that the likelihood of a visitor making a generous voluntary contribution towards a particular cause was positively influenced by the awareness of a particular need (Bendapudi et al, 1996). Both the awareness of a particular need, and the positive positioning of the BM brand in the not-for-profit sector would result in an improvement in the familiarity of individual visitors and non-visitors with the BM and its offerings. Thus, one hindering factor behind the level of voluntary contributions at the BM relates to limited information provision and time availability that affect trust levels among individuals and the organization as opposed to individual resistance to the BM's cause.

The level of association with the arts and culture has proven an equally significant influence on individual voluntary contribution levels. Cultural affiliation (both specific to the BM ('Friends of the BM') and general (with respect to arts and culture) tends to have a very positive effect on voluntary contribution levels. In particular, the empirical evidence presented in Table 4 indicates that both those who have a specific association with the BM (members of the 'Friends of the BM') and those who have an association with the arts and culture in general are more likely to voluntarily contribute during their visit than are those who have no association with cultural organizations at all. In other words, networks (either formal or informal), and cultural membership appear to be important instigators of pro-social behaviour through voluntary giving. This piece of evidence should be particularly useful to practitioners given that cultural membership ('culturiocity') and participation are an important antecedent variable for distinguishing culturally motivated from nonculturally motivated individuals in the same way as 'religiosity' is an important antecedent variable for predicting charitable donations for religious purposes (Ranganathan and Henley, 2008).

Evidence from Table 4 shows that respondents directly associated with the $\mathrm{BM}$ were $6.4 \%$ more likely to donate anything up to $£ 3.99$ and $21.5 \%$ more likely to donate more than $£ 4$ than respondents with no association with the $\mathrm{BM}$ whatsoever. Similarly, respondents with a general association with arts and 
culture were also more likely to contribute voluntarily to the BM (6\% more likely to donate up to $£ 3.99$ and $25.8 \%$ more likely to donate more than $£ 4$ than those respondents with no general association with the arts and culture). Indeed, the results suggest that the BM network should be used to attract more donations not only from its own pool of supporters, but also from the reserves of supporters from other cultural organizations. What is important here is the existence of a social network of individuals who share the same norms and values. The literature suggests that individuals with a strong association with a particular cause or organization develop strong pro-social behaviour. Thus, the existence of formal and informal communities of participation among museumgoers seems to have a positive effect on their reference group and the action of the organization as a result of greater involvement and scrutiny from within. This finding correlates with the findings of Kanagaretnam et al (2010) that transparency in operations has a significant effect on voluntary contribution levels.

Table 4 shows that respondents living in the least affluent parts of London (Central and East London) are also the ones most likely to donate nothing (£0) to the $\mathrm{BM}$ (by $9.7 \%$ and $12 \%$, respectively, as compared to respondents living outside London). These empirical results indicate that individuals living in deprived communities exhibit a lower willingness to engage into acts of reciprocity. In a way, these are rather anticipated results that tend to confirm the rationale for the direction of recent policymaking in the area. As suggested earlier, less well-off individuals try to deny responsibility for the arts and culture.

The effect of marital status on voluntary contributions is a rather interesting one. More particularly, the recent rise in single-parent families means that there is less room for participation in charitable activity for single households. Re-married individuals are the only ones to exhibit a higher intention to contribute voluntarily more than $£ 4$ to the BM (22.6\% more likely than single households). At the same time, they are the least likely group of individuals to donate nothing to the BM cause (19.7\% less likely to donate $£ 0$ than single individuals). These results tend to concur with the general literature in that marriage is found to be strongly correlated to higher level of voluntary contributions (Van Slyke and Brooks, 2005).

Regarding the effect of the age variable on voluntary contribution levels, the empirical results mark a distinctive break in behavioural patterns between young and middle-aged respondents, on the one hand, and senior or mature respondents, on the other. Thus, mature and senior visitors are less likely to contribute voluntarily nothing to the $\mathrm{BM}$ as compared to young respondents (by almost $24 \%$ and $18.5 \%$, respectively). At the same time, senior and mature respondents are $(28.5 \%$ and $20.5 \%$, respectively) more likely to contribute voluntarily over $£ 4$ to the BM than their younger counterparts. Middle-aged visitors are less likely to donate nothing than younger visitors, but they do not seem to exhibit any discernible impact on positive voluntary contribution levels.

The above results are consistent with the evidence presented in the literature. In particular, Schervish et al (2002) and Okunade et al (1994) agree that levels of charitable giving increase with age. The empirical results from the current investigation follow the same direction as the results reported by Andreoni 
(2001) and Hoge and Yang (1994). Accordingly, mature and senior visitors make voluntary contributions to the BM due to a sense of obligation to provide something back to society.

Finally, the results provide information on the impact of the income variable on marginal willingness to contribute levels. As anticipated, the results from Table 4 indicate that respondents on low and middle-range incomes are more likely to donate nothing (£0) during their visit to the $\mathrm{BM}$ than those respondents with high income levels (by approximately 5\% and 3\%, respectively). Equally, respondents on low and average income levels are more likely to contribute voluntarily small amounts of money (up to £1.99) than high-income respondents (3.4\% and $2.3 \%$, respectively). These results concur with the evidence presented in the literature (Hoge and Yang, 1994; Auten et al, 2002; Schervish et al, 2002; Smith and McSweeney, 2007). Similar to the case of place of residence, it seems that less wealthy individuals are denying any responsibility for not-for-profit cultural tourist organizations. Their perceived indifference (based on financial grounds) has an effect on donation levels.

\section{Policy implications}

The discussion so far has focused on who is more likely to contribute voluntarily towards the BM and by how much. An analysis of the policy implications of that discussion will shed light on the direction of future policymaking for notfor-profit cultural tourist attractions.

Infrequent visitors to the BM (first-time and accidental) were less familiar with the collections of the BM and so were less likely to make a voluntary contribution. Such a relationship may be attributable to the lack of awareness on the part of adjunct visitors with the attraction and its problems. Conceptually speaking, this suggestion echoes what Jaffry and Apostolakis (2011) reported with respect to current levels of information among first-time and infrequent visitors to the BM. According to Jaffry and Apostolakis (2011), firsttime or adjunct visitors in particular were more likely to contribute voluntarily for a bigger information desk. This piece of information presents cultural resource managers with a unique opportunity. Rather than focusing exclusively on actual visitors' awareness levels, managers could concentrate on raising awareness levels among accidental and first-time visitors. Implicitly, such a policy makes sense given that adjunct and accidental visitors' information needs are much greater than frequent visitors' requirements.

With regard to voluntary contributions, the above policy initiative has two notable advantages. First, actual and potential visitors would become more familiar with the specific context of the resource and would be more likely to voluntarily contribute towards the cause if and when they decided to visit. Second, cultural not-for-profit tourist organizations could target directly those who use the electronic resources on the Internet by presenting the BM case to them and soliciting contributions. This would be a novel initiative for cultural and heritage tourism resources, although it has been used in other service contexts (for example, Wikipedia has asked users to make voluntary contributions to support the continuation of the service). 
The fact that infrequent visitors are more likely to avoid making voluntary contributions towards cultural resources could be down to matters of efficacy. In other words, infrequent visitors may question the difference that their voluntary contribution could make overall. So, when individuals (especially those who do not have a strong association with the cultural organization) perceive that their contribution is not going to make a difference, they will be less likely to donate (Diamond and Kashyap, 1997). In such cases, people consciously downplay the effectiveness and significance of their contributions (Bekkers, 2006; Vesterlund, 2006). One way to address the issue of efficacy is to increase individuals' confidence in the organization. Cultural and arts managers and policymakers could achieve this by explaining to visitors the impact that their voluntary contribution is likely to make. Introducing more transparency as to where the money collected from voluntary contributions goes, as well as reassuring individuals that the money collected will serve visitors' needs and goals, could transform the act of voluntary donations towards cultural resources from a 'hard sell' into an act of obligation. According to Bekkers (2006), those individuals with a higher degree of faith and confidence in the particular cause are more likely to contribute voluntarily to it.

The empirical analysis tends to confirm the evidence from the literature regarding place of residence or origin. First, individuals from Central London are on average less affluent than visitors coming from other parts of London. One would imagine that cultural resource managers cannot do much to alleviate the impact of this factor. However, when targeting a less well-off part of the population the focus is on providing 'value for money'. Providing targeted fringe benefits (Buraschi and Cornelli, 2003) could attract less well off members of society to the BM, while at the same time increasing voluntary contributions. When the provision of these fringe benefits (such as subsidized prices at the gift shop, or special events catering for the local community) is matched with selected groups in the population, the level of voluntary contributions is likely to increase (Harbaugh, 1998).

Evaluating the results regarding the influence of the two affiliation variables (member of 'Friends of the BM' and member of other culture-related organizations) generates some interesting points for discussion. The empirical evidence from earlier parts of the paper suggests that respondents with a strong affiliation with cultural organizations and communities tend to be more generously disposed towards the BM. Essentially, this point indicates that individuals choose to contribute voluntarily to cultural resources due to the existence of participation networks that influence trust and donor behaviour (Wilson and Musick, 1998; Brown, 2001; Brooks, 2005). This concurs with the evidence from the literature (Schervish and Havens, 1998; Reed and Selbee, 2000; Apinunmahakul and Devlin, 2008). We maintain that membership of these social and cultural networks (formal and informal) has a very positive effect on voluntary contribution levels for not-for-profit cultural organizations. Being part of these communities or social networks reduces transaction costs. Therefore, it acts as a stimulant to voluntary contributions.

As far as the BM is concerned, the above evidence should present a very clear and direct policy initiative. The managers of the BM should acknowledge the fact that investing in cultural network enhancing infrastructure could potentially increase the likelihood of voluntary contributions from future and 
actual visitors to the BM. This is because participants in these networks represent individuals that are willing to reciprocate to cultural organizations in order to increase the provision of public goods. Targeting these individuals could become a very efficient way of generating a higher amount of voluntary contributions. As part of that initiative, the BM could utilize its nature and impact as the leading cultural heritage tourist resource in the UK in order to form links and partnerships with other museums and cultural organizations in the UK and abroad. The Trustees of the BM have implicitly taken note of the above points. As a result, they are currently putting more effort into strengthening links with individual donors to the BM (for example, the initiative behind the American Friends of the British Museum). In addition to that, the $\mathrm{BM}$ is actively building a network of collaborations with other institutions (nationally and internationally). As part of this initiative it has developed a number of collaborative programmes (with museums in the UK and museums elsewhere in the world) to strengthen lines of communication between organizations and visitors.

Finally, there is the behaviour of the mature and senior segments of respondents. The results indicate that mature and senior visitors are more likely to voluntarily contribute than younger visitors. This indicates that cultural attractions should prioritize this segment of the population in their strategies to attract donations. Mature and senior visitors are more likely to contribute voluntarily because of their greater discretionary resources and sense of commitment. Particularly with respect to the sense of commitment, culture managers could initiate actions aimed at 'fostering altruism as well as communal relations among supporters' (Farsides, 2005).

\section{Conclusion}

This paper examines the factors affecting individual voluntary contribution levels in the cultural tourism sector. In the light of UK government decision making with respect to free-entry attractions (December 2001), this empirical study represents a significant contribution to the discussion. As a result of the recent worldwide pressures on government funding of arts and cultural heritage attractions (Anderson, 1998; Bailey and Falconer, 1998; Trupiano, 2005), coupled with calls for a greater degree of accountability and justification of the expenditure of public money, cultural heritage attractions now have to attract income generated through their own activities to sustain their activities at current levels. The paper addresses issues of trust and social commitment to provide a solution to the 'social dilemma' affecting individual voluntary contributions to cultural heritage resources.

In order to provide a solution to this social dilemma, the research adopts the $\mathrm{BM}$ as a case study for the examination of pro-social behaviour. We use data generated from a survey questionnaire at the BM in London to identify the likelihood of individuals making voluntary contributions at the gates. In particular, we have to explain how arts and culture not-for-profit tourist organizations can identify and target those individuals most likely to voluntarily contribute towards the arts and culture. Our analysis employs an ordered probit model to satisfy this requirement. 
On the basis of the empirical information gathered, we put forward a number of policy suggestions for cultural tourism managers and decision makers. First, the Trustees of the BM should engage in targeted marketing to those individuals with a high degree of 'culturiocity'. These are the people most likely to engage actively with arts and culture. Second, we suggest that the Trustees should go against the current tide with respect to cultural heritage tourist resources and should focus on the senior/mature market. Given that this market represents the majority of visitors to museums and cultural tourist attractions, it is surprising that the BM has not targeted them so far. Finally, we propose that the Trustees of the BM invest in a cultural network enhancing infrastructure that could encourage actual and potential visitors to voluntarily contribute towards the BM. Engaging with individuals belonging in other cultural organizations could minimize transaction costs and increase the likelihood of voluntary contributions from actual and future visitors.

\section{References}

Anderson, R. (1998), 'Is charging economic?', Journal of Cultural Economics, Vol 22, pp 179-187. Andreoni, J. (2001), 'The economics of philanthropy', in Smelsert, N., and Baltes, P., eds, International Encyclopedia of the Social and Behavioural Sciences, Elsevier, London, pp 11369-11376.

Apinunmahakul, A., and Devlin, R. (2008), 'Social networks and private philanthropy', Journal of Public Economics, Vol 92, pp 309-328.

Atkinson, A. (2009), 'Giving overseas and public policy', Journal of Public Policy, Vol 93, pp 647653.

Auten, G., and Joulfaian, D. (1996), 'Charitable contributions and intergenerational transfers', Journal of Public Economics, Vol 59, No 1, pp 55-68.

Auten, G., Sieg, H., and Clotfelter, C. (2002), 'Charitable giving, income and taxes: an analysis of panel data', American Economic Review, Vol 92, pp 371-382.

Bailey, S., and Falconer, P. (1998), 'Charging for admission to museums and galleries: a framework for analysing the impact on access', Journal of Cultural Economics, Vol 22, pp 167-177.

Brooks, A. (2005), 'Does social capital make you generous?', Social Science Quarterly, Vol 29, pp 2549.

Bekkers, R. (2006), 'Traditional and health related philanthropy: the role of resources and personality', Social Psychology Quarterly, Vol 68, No 4.

Bendapudi, N., Singh, S., and Bendapudi, V. (1996), 'Enhancing helping behavior: an integrative framework for promotion planning', Journal of Marketing, Vol 60, pp 33-49.

Bertacchini, E., Santagata, W., and Signorello, G. (2010), 'Loving cultural heritage private individual giving and prosocial behaviour', Nota di Lavoro, Fondazione Eni Enrico Mattei.

Bille Hansen T. (1997), 'The willingness-to-pay for the royal theatre in Copenhagen as a public good', Journal of Cultural Economics, Vol 21, pp 1-28.

Brown, E. (2001), 'Making philanthropy work: social capital and human capital as predictors of household giving', Claremont Colleges Working Papers 2001 - 37, December.

Brown, E., and Ferris, J. (2002), 'Social capital in Los Angeles: findings from the social capital community benchmark survey', Centre of Philanthropy and Public Policy, Los Angeles, CA.

Buraschi, A., and Cornelli, F. (2003), Donations, London Business School, Institute of Finance.

Caygill, M., and Leese, M. (1993), 'A survey of visitors to the British Museum (1992-3)', British Museum Occasional Paper 101, The British Museum, London.

Conlin, M., Lynn, M., and O’Donoghue, T. (2003), 'The norm of restaurant tipping', Journal of Economic Behaviour and Organisation, Vol 52, pp 297-321.

Conner, M., Norman, P., and Bell, R. (2002), 'The theory of planned behaviour and healthy eating', Health Psychology, Vol 21, pp 195-201.

De Kremer, D. (2003), 'Noneconomic motives predicting cooperation in public good dilemmas: the effect of received respect on contributions', Social Justice Research, Vol 16, No 4, pp 367-377.

Department for Culture, Media and Sport (DCMS) (2000), 'Centres for social change: museums, galleries and archives for all', DCMS report, London. 
Department for Culture, Media and Sport (DCMS) (2002), 'Free admission to museums', DCMS press release, 7 January, London.

Department for Culture Media and Sport (DCMS) (2005), 'Understanding the future: museums and 21 st century life - the value of museums', DCMS report, London.

Diamond, W., and Kashyap, R. (1997), 'Extending models of prosocial behaviour to explain alumni contributions', Journal of Applied Social Psychology, Vol 27, No 10, pp 915-928.

Dokko, J. (2008), 'Does the NEA crowd out private charitable contributions to the arts?', Finance and Economics Discussion Series, Division of Research and Statistics and Monetary Affairs, Federal Reserve Board, Washington, DC.

Farsides, T. (2005), “How can we help" rather than "give us your money”, Economic and Social Research Council (ESRC) Seminar Series, Mapping the Public Policy Landscape, ESRC, Swindon.

Fenton, N., Passey, A., and Herms, L. (1999), 'Trust, the voluntary sector and civil society', International Journal of Sociology and Social Policy, Vol 19, No 7/8, pp 21-42.

Frey, B., and Meier, S. (2004), 'Pro-social behaviour in a natural setting', Journal of Economic Behaviour and Organisation, Vol 54, pp 65-88.

Garbarino, E., and Johnson, M. (1999), 'The different roles of satisfaction, trust and commitment in consumer relationships', Journal of Marketing, Vol 63, pp 70-87.

Greene, W.H. (2000), Econometric Analysis, 4th edn, Prentice Hall, Upper Saddle River, NJ.

Gurian, E.H. (2005), 'Free at last: a defence in favour of free admission', Museum News, Vol 84, No 5, pp 33-35.

Harbaugh, W. (1998), 'What do donations buy? A model of philanthropy based on prestige and warm-glow', Journal of Public Economics, Vol 67, pp 269-284.

Heilbrun, J., and Gray, C. (2001), The Economics of Arts and Culture, 2nd edn, Cambridge University Press, Cambridge.

Hibbert S., (2005), 'Why do people give to charity - and why don't others?', Economic and Social Research Council (ESRC) Seminar Series, Mapping the Public Policy Landscape, ESRC, Swindon.

Hoge, D. (1995), 'Explanations for current levels of religious giving', New Directions for Philanthropic Fundraising, Vol 7, pp 51-70.

Hoge, D., and Yang, F. (1994), 'Determinants of religious giving in American denominations: data from two nationwide surveys', Review of Religious Research, Vol 36, No 2, pp 123-142.

Holmes, J. (2009), 'Prestige, charitable deductions and other determinants of alumni giving: evidence from a highly selective liberal arts college', Economics of Education Review, Vol 28, pp 1828.

Iannacone, L. (1998), 'Introduction to the economics of religion', Journal of Economic Literature, Vol 36, No 3, pp 1465-1495.

Jaffry, S., and Apostolakis, A. (2011), 'Evaluating individual preferences for the British Museum', Journal of Cultural Economics, Vol 35, No 1, pp 49-75.

Johnson, M., and Garbarino, E. (1999), 'Customers of performing arts organisations: are subscribers different from nonsubscribers', International Journal of Nonprofit and Voluntary Sector Marketing, Vol 6, No 1, pp 61-77.

Kanagaretnam, K., Mestelman, S., Khalid Nainar, S.M., and Shehata, M. (2010), 'Trust and reciprocity with transparency and repeated interactions', Journal of Business Research, Vol 63, pp 241-247.

Kockelman, K. and Kweon, Y. (2002), 'Driver injury severity: an application of ordered probit models', Accident Analysis and Prevention, Vol 34, No 4, pp 313-321.

Krishnamurthy, S., and Tripathi, A. (2009), 'Monetary donations to an open source software platform', Research Policy, Vol 38, pp 404-414.

Labonne, J., and Chase, R. (2010), 'A road to trust', Journal of Economic Behaviour and Organization, Vol 74, pp 253-261.

Lampi, E., and Orth, M. (2009), 'Who visits the museums? A comparison between stated preferences and observed effects of entrance fees', Kyklos, Vol 62, No 1, pp 85-102.

Maddison, D., and Foster, T. (2003), 'Valuing congestion costs in the British Museum', Oxford Economic Papers, Vol 55, pp 173-190.

Mesch, D., Rooney, P., Steinberg, K., and Denton, B. (2002), 'The effects of race, gender and marital status on giving and volunteering in Indiana', Nonprofit and Voluntary Sector Quarterly, Vol 35, No 4, pp 565-587.

Okunade, A., Wunnava, P., and Walsh, R. (1994), 'Charitable giving of alumni: micro data evidence from a large public univesity', American Journal of Economics and Sociology, Vol 53, No 1, pp 7384. 
Oliveira, P., and Pereira, P. (2008), 'Who values what in a tourism destination? The case of Madeira Island', Tourism Economics, Vol 14, No 1, pp 155-168.

Piper, G., and Schnepf, S. (2007), 'Gender differences in charitable giving', Institute for the Study of Labour (IZA), Discussion paper No. 3242, IZA, Bonn.

Putnam, R. (2000), Bowling Alone: The Collapse and Revival of American Community, Simon and Schuster, New York.

Ranganathan, S., and Henley, W. (2008), 'Determinants of charitable donation intentions: a structural equation model', International Journal of Non - Profit and Voluntary Sector Marketing, Vol 13, pp 1-11.

Reed, P., and Selbee, L. (2000), 'Distinguishing characteristics of active volunteers in Canada', Nonprofit and Voluntary Sector Quarterly, Vol 29, No 4, pp 571-592.

Schervish, P., and Havens, J. (1998), 'Social participation and charitable giving: a multivariate analysis', Voluntas, Vol 8, No 3, pp 235-260.

Schervish, P., O'Herlihy, M., and Havens, J. (2002), 'Charitable giving: how much, by whom, to what and how?', in Powel, W., and Steinberg, R., eds, The Non-Profit Sector: A Research Handbook, Yale University Press, New Haven, CT.

Schlegelmilch B.C. (1998), 'Marketing Ethics; An International Perspective', John Wiley and Sons Ltd, London.

Smith, J., and McSweeney, A. (2007), 'Charitable giving: the effectiveness of a revised theory of planned behaviour model in predicting donating intentions and behaviour', Journal of Community and Applied Psychology, Vol 17, pp 363-386.

Steiner, F., (1997), 'Optimal pricing of museum admission', Journal of Cultural Economics, Vol 21, pp 307-333.

Steele, P. (2010), 'DCMS funding for sponsored bodies and renaissance cut by 15\%', The Museums Journal (http://www.museumsassociation.org/museums-journal/news/20102010-comprehensivespending-review-museums, accessed 20 October 2010).

Supphellen, M., and Nelson, M. (2001), 'Developing, exploring, and validating a typology of private philanthropic decision making', Journal of Economic Psychology, Vol 22, No 5, pp 573-603.

Tepper, S. (2005), 'Why public funding for the arts needs to find a new frontier', Wealth Management, 1st Quarter, pp 30-31.

Tohmo, T. (2004), 'Economic value of a local museum: factors of willingness-to-pay', Journal of SocioEconomics, Vol 33, pp 229-240.

Trupiano, G. (2005), 'Financing the culture in Italy', Journal of Cultural Heritage, Vol 6, pp 337343.

Vesterlund, L. (2006), 'Why do people give?', in Steinberg, R., and Powell, W., eds, The Nonprofit Sector, 2nd edn, Yale University Press, New Haven, CT.

Van Slyke, D., and Brooks, A. (2005), 'Why do people give? New evidence and strategies for nonprofit managers', American Review of Public Administration, Vol 35, No 3, pp 199-222.

Von Neumann, J., and Morgenstern, O. (1944), Theory of Games and Economic Behaviour, Princeton University Press, Princeton, NJ.

Yang, C., and Raehsler, R. (2005), 'An economic analysis on intermediate microeconomics: an ordered probit model', Journal for Economic Educators, Vol 5, No 3, pp 1-11.

Webb, D., Green, C., and Brashear, T. (2000), 'Development and validation of scales to measure attitudes influencing monetary donations to charitable organizations', Journal of the Academy of Marketing Science, Vol 28, No 2, pp 299-309.

Wilson, J. (2000), 'Volunteering', Annual Review of Sociology, Vol 26, pp 215-240.

Wilson, A., and Pimm, G. (1996), 'The tyranny of the volunteer: the care and feeding of voluntary workforces', Management Decision, Vol 34, No 4, pp 24-40.

Wilson, J., and Musick, M. (1998), 'The contribution of social resources to volunteering', Social Sciences, Vol 79, pp 799-814. 